Article

\title{
Room-Temperature Self-Standing Cellulose-Based Hydrogel Electrolytes for Electrochemical Devices
}

\author{
Iñaki Gomez *, Yolanda Alesanco ${ }^{\circledR}$, Jose Alberto Blázquez, Ana Viñuales \\ and Luis C. Colmenares *(D)
}

CIDETEC, Basque Research and Technology Alliance (BRTA), Paseo Miramón 196, 20014 Donostia-San Sebastián, Spain; yalesanco@cidetec.es (Y.A.); ablazquez@cidetec.es (J.A.B.); avinuales@cidetec.es (A.V.)

* Correspondence: igomez@cidetec.es (I.G.); lcolmenares@cidetec.es (L.C.C.); Tel.: +34-943309022 (I.G. \& L.C.C.)

Received: 5 October 2020; Accepted: 11 November 2020; Published: 13 November 2020

\begin{abstract}
The trend of research towards more sustainable materials is pushing the application of biopolymers in a variety of unexplored fields. In this regard, hydrogels are attracting significant attention as electrolytes for flexible electrochemical devices thanks to their combination of ionic conductivity and mechanical properties. In this context, we present the use of cellulose-based hydrogels as aqueous electrolytes for electrochemical devices. These materials were obtained by crosslinking of hydroxyethyl cellulose (HEC) with divinyl sulfone (DVS) in the presence of carboxymethyl cellulose (CMC), creating a semi-IPN structure. The reaction was confirmed by NMR and FTIR. The small-amplitude oscillatory shear (SAOS) technique revealed that the rheological properties could be conveniently varied by simply changing the gel composition. Additionally, the hydrogels presented high ionic conductivity in the range of $\mathrm{mS} \mathrm{cm}^{-1}$. The ease of synthesis and processing of the hydrogels allowed the assembly of an all-in-one electrochromic device (ECD) with high transmittance variation, improved switching time and good color efficiency. On the other hand, the swelling ability of the hydrogels permits the tuning of the electrolyte to improve the performance of a printed $\mathrm{Zinc} / \mathrm{MnO}_{2}$ primary battery. The results prove the potential of cellulose-based hydrogels as electrolytes for more sustainable electrochemical devices.
\end{abstract}

Keywords: cellulose; hydrogel; electrolyte; room-temperature; electrochemical devices; electrochromic devices; zinc aqueous batteries

\section{Introduction}

Wearable electronics with specific features (miniaturizing, flexibility and custom shape) are of increasing interest in applications such as medical sensing devices and smart labels in the frame of the rising of IoT [1]. These systems include several flexible electrochemical devices (i.e., sensors, batteries, electrochromic, electronics), whose performance is not affected under different mechanical stresses [2]. These technologies rely on soft and flexible materials where hydrogels have shown up as promising electrolyte systems $[3,4]$. These materials consist of tridimensional polymer networks that can accommodate a large amount of water within the interstices of the structure, mainly through polar or ionic bonding from functional groups in the backbone [5,6]. In this way, hydrogels combine the features of aqueous electrolytes (ionic conductivity and interfacial contact) with the mechanical properties of polymers, while preventing the principal drawbacks of aqueous electrolytes, namely the risk of leakage and fast evaporation. Besides, the versatility of polymer chemistry can confer advanced functionalities to hydrogels (i.e., improved water retention, higher ionic conductivity, rubbery stretchability, self-healing ability) to obtain engineered materials for specific applications $[5,6]$. All in all, the most widely used polymeric materials as a hydrogel matrix are composed of synthetic monomers 
from non-renewable sources. This issue, together with the increasingly worrying E-waste problem, has boosted the research on more sustainable materials for electrochemical devices [7]. In this regard, bio-source polymers offer a variety of materials with a wide range of different characteristics, such as hydrophilicity, good mechanical properties and easy chemical modification ability. These features, summed to their inherent biodegradability, and their high abundance makes biopolymers a suitable choice for sustainable hydrogel electrolytes [8-10].

Among the large variety of biomaterials that nature offers, cellulose is the most abundant biopolymer on Earth, present as one of the main structural components of plants and seaweeds. Composed of D-anhydroglucopyranose repeating units linked by $1,4-\beta$ glycosidic bonds, it possesses a high amount of hydroxyl groups in the linear polymeric backbone that confers several characteristics, such as high mechanical properties, chemical modification ability and high hydrophilicity [11]. These features, summed with the inherent biocompatibility and biodegradability of cellulose, have promoted tremendous research on cellulose-based hydrogels $(\mathrm{CBH})$ in health sciences such as tissue engineering, drug delivery and wound dressing [12]. Besides, CBHs based on CMC present superabsorbent behavior, promoting their use in applications such as water cleaning, water reservoirs for agriculture and personal hygiene items $[8,13]$. Despite the benefits of cellulose as a hydrogel matrix, the use of $\mathrm{CBHs}$ in electrochemical devices as electrolytes is relatively scarce. However, the trend of research in materials and devices towards a circular economy is pushing the application of biopolymers in a variety of unexplored field [14].

The high amount of intra- and intermolecular H-bonds between macromolecules promotes strong crystalline structures, making native cellulose an insoluble and intractable material [15]. Specific solvent systems can effectively break these interactions and dissolve cellulose, which allows for its processing. For instance, Kasprzak and coworkers used an ionic liquid/DMSO solvent system to dissolve cellulose to fabricate both hydrogel electrolytes and composite electrodes for an electrochemical double-layer capacitors (EDLC) [16]. More recently, Yan and coworkers presented flexible capacitors by coagulating a cellulose solution in $\mathrm{ZnCl}_{2}$ water-in-salt media [17]. Through these strategies, the main structural support relies on hydrophobic interaction and/or entanglement forces that confer limited mechanical stability. In this regard, Navarra and coworkers studied the feasibility of CBHs as electrolytes obtained through the crosslinking of a cellulose solution in a $\mathrm{NaOH} /$ urea system with epichlorhydrin [18]. More recently, Yan and coworkers used this system as an electrolyte for an asymmetric capacitor, showing that high energy density as well as high power capacity were achieved [19]. The main drawback of these approaches relies on the liquid media needed for the dissolution of cellulose, which is unsuitable for alternative electrochemical devices such as batteries and/or electrochromic (ECDs). In this regard, cellulose derivatives offer a variety of properties thanks to their functional groups introduced through the modification of the hydroxyl groups of the backbone. In this way, several water-soluble cellulosic materials can be obtained such as methyl cellulose (MC), hydroxyethyl cellulose (HEC) and carboxymethyl cellulose (CMC). Shi and coworkers took advantage of the hydrophobic interactions of methyl cellulose (MC) and hydroxypropyl cellulose (HPC) in order to obtain thermoresponsive electrolytes for safer energy storage devices [20]. Gajewski and Béguin proved that a CBH based on CMC improved the performance of electrochemical capacitors when comparing with commercial separators such as Celgard or Whatman [21]. However, these materials lack dimensional stability, which hinders their potential use for flexible devices.

In this context, we present the synthesis of self-standing cellulose-based hydrogels and their application as electrolytes for electrochemical devices. These materials were obtained through the crosslinking reaction of cellulose derivatives with divinyl sulfone (DVS) in aqueous media. This approach has been extensively reported as an effective method to obtain hydrogels for tissue engineering, biomedicine and bioelectronics [22-25]. All in all, this work gives a deeper insight into the impact of the material composition on the rheological parameters. Moreover, this is the first report to explore the potential of these hydrogels as electrolytes for electrochemical devices. In this regard, the ease of hydrogel synthesis favors the assembly of all-in-one electrochromic devices, 
and their swelling behavior allows adjusting the electrolytic solution for a printed aqueous zinc battery. These results show the potential of $\mathrm{CBH}$ as electrolytes for a variety of electrochemical devices as well as processing methods such as tape casting or printing techniques.

\section{Materials and Methods}

\subsection{Materials}

Carboxy methyl cellulose (DuPont, Wilmington, DE, USA. 2000 Pa, DS: 0.82-0.95), hydroxyethyl cellulose (Natrosol ${ }^{\mathrm{TM}}$, Ashland Global, Covington, KY, USA), divinyl sulfone (TCI chemicals, Tokyo, Japan, 96\%), ethyl viologen dibromide (Sigma-Aldrich, St. Louis, MO, USA 99\%), potassium ferrocyanide (Sigma-Aldrich, 98.5\%), potassium ferricyanide (Sigma-Aldrich, 99\%) and $\mathrm{ZnCl}_{2}$ (Sigma-Aldrich, $>98 \%$ ) were used without further purification.

\subsection{Synthesis of Cellulose-Based Hydrogel (General Procedure)}

The precursor of the cellulose-based hydrogel was prepared by dissolving the proper amount of $\mathrm{CMC}$ and HEC in $9.4 \mathrm{~g}$ of a $\mathrm{KOH}$ solution. This cellulose-based precursor solution was stirred until a viscous, clear and transparent medium was obtained. Subsequently, DVS was added and the solution was stirred until gelification of the media was observed.

\subsection{Characterization Methods}

The NMR spectra were recorded in a Bruker $500 \mathrm{MHz}$ spectrometer with deuterated water as solvent. For the hydrogel, $0.01 \mathrm{~g}$ of HEC was dissolved in $10 \mathrm{mM} \mathrm{KOH}$ followed by the addition of $0.01 \mathrm{~g}$ of DVS. The mixture was quickly placed into the NMR tube for the full reaction.

The ATR-FTIR spectra were obtained in the wavenumber range from 4000 to $400 \mathrm{~cm}^{-1}$ over 64 scans with a resolution of $4 \mathrm{~cm}^{-1}$ using a 4100LE FTIR (Jasco, Hachioji-shi, Tokyo, Japan). The samples were dried in the oven until constant weight.

Rheological measurements were carried out in a TA instruments AR2000ex Rheometer employing parallel plates of $40 \mathrm{~mm}$ diameter. Time sweep experiments were performed with frequency and strain values set at $1 \mathrm{~Hz}$ and $1 \%$, respectively. Temperature was kept at $25^{\circ} \mathrm{C}$. For frequency and strain sweeps, the hydrogels were cured in the parallel plates at $25^{\circ} \mathrm{C}$. Strain sweeps were performed at a frequency of $1 \mathrm{~Hz}$ in a range of strains from $0.01 \%$ to $100 \%$. Frequency sweeps were performed at a strain of $1 \%$ in a range of 0.001 to $100 \mathrm{~Hz}$.

Ionic conductivity of hydrogels was determined by electrochemical impedance spectroscopy (EIS) in a potentiostat Solartron Analytics (Farnborough, UK) with a CR2032 coin cell setup. The precursor solution of the desired hydrogel electrolyte was placed between two stainless steel disks, separated by a PET ring (thickness of $0.4 \mathrm{~mm}$; inner diameter of $11 \mathrm{~mm}$ ). After the coin cell was sealed, the hydrogel electrolytes were allowed to react for $90 \mathrm{~min}$. Electrochromic properties of the ECDs were evaluated with a Jasco V-570 UV-Vis Spectrophotometer (Jasco, Hachioji-shi, Tokyo, Japan) provided with a films holder accessory for solid samples, while the devices were connected to a Biologic MPG potentiostat/galvanostat (BioLogic Science Instruments, Auvergne-Rhône-Alpe, France) as a direct current source. UV-Vis spectra were obtained in transmission mode using air as the background.

The photographs of the ECDs were acquired using a Canon IXUS 105 camera while the ECDs were lit with a fluorescent light source (Phillips TL-D 80 18W/840), without the employment of flash (focal distance $=5 \mathrm{~mm}$, maximum opening $=3$ and exposition time $=30-50 \mathrm{~s}$ ).

The printed batteries were tested in a Biologic MPG potentiostat/galvanostat. The galvanostatic discharge experiments were performed at 50 and $100 \mu \mathrm{A}$. For the intermittent discharge experiment, power pulses of $100 \mu \mathrm{W}$ for $6 \mathrm{~s}$ and $30 \mathrm{~s}$ of resting in open circuit potential (OCV) were applied. 


\subsection{Assembly of All-in-One ECDs}

To a cellulose-based precursor solution (CMC, HEC and $\mathrm{KOH}$ solution), ethyl viologen dibromide $(20 \mathrm{mM})$ and a 1:1 mixture of potassium ferrocyanide and ferricyanide $(6 \mathrm{mM})$ were added. This formulation was stirred until a homogeneous solution was obtained. DVS was purified by passing it through the inhibitor remover column. Detailed information regarding the assembly process of all-in-one ECDs can be found in previously published work [26]. Briefly, the cellulose-based electrochromic hydrogel was spread on the ITO-coated side of one of the ITO-PET substrates provided with a spacer along the whole perimeter (double-sided adhesive tape frame of $220 \mu \mathrm{m}$ thick and $3 \mathrm{~mm}$ wide). Then, it was covered with the other ITO-PET electrode substrate, applying light pressure in order to guarantee the adhesion between both electrodes.

\subsection{Assembly of Printed Batteries}

Printed zinc/ $\mathrm{MnO}_{2}$ batteries were kindly supplied by Varta Microbattery $\mathrm{GmbH}$ (Ellwangen, Germany). A precursor of cellulose-based electrolytes ( $0.2 \mathrm{~g}$ of CMC, $0.2 \mathrm{~g}$ of HEC and $0.2 \mathrm{~g}$ of DVS in $9.4 \mathrm{~mL}$ of $20 \mathrm{mM}$ of $\mathrm{KOH}$ ) was casted onto the electrodes using a custom-made double-taped mask. The solution was allowed to react for $90 \mathrm{~min}$. Afterwards, the battery was sealed with another homemade mask. For printed batteries tested with the $\mathrm{ZnCl}_{2}$ electrolyte, the battery's electrodes were coated with the cellulose-based electrolyte. After $90 \mathrm{~min}$ of reaction, the coated battery was dried in an oven $\left(30^{\circ} \mathrm{C}\right)$ until constant weight. Finally, the film was swelled, adding a given volume of $1 \mathrm{M}$ of $\mathrm{ZnCl}_{2}$ electrolyte, and then the battery was sealed.

\section{Results and Discussion}

\subsection{Synthesis and Physicochemical Characterization}

Cellulose-based hydrogels (CBH) were obtained by the crosslinking of cellulose derivatives with divinyl sulfone (DVS) at room temperature. The reaction proceeded by the dissolution of carboxymethyl cellulose (CMC) and hydroxyethyl cellulose (HEC) in alkaline aqueous media $(12<\mathrm{pH}<13)$, followed by the addition of the crosslinking agent (DVS). After a short period of time (ca. $10 \mathrm{~min}$ ) stirring, the reaction media solidified, obtaining a transparent gel. Self-standing transparent and soft hydrogel films were obtained by drop casting the precursor solution upon a Petri dish and leaving it for $60 \mathrm{~min}$ (Figure 1a). The crosslinking mechanism involved the deprotonation of the hydroxyl groups of the cellulose derivatives induced by the $\mathrm{pH}$ of the media and the subsequent attack of the alkoxy anions on the electron-deficient vinyl groups from the DVS [27] (Figure 1b).

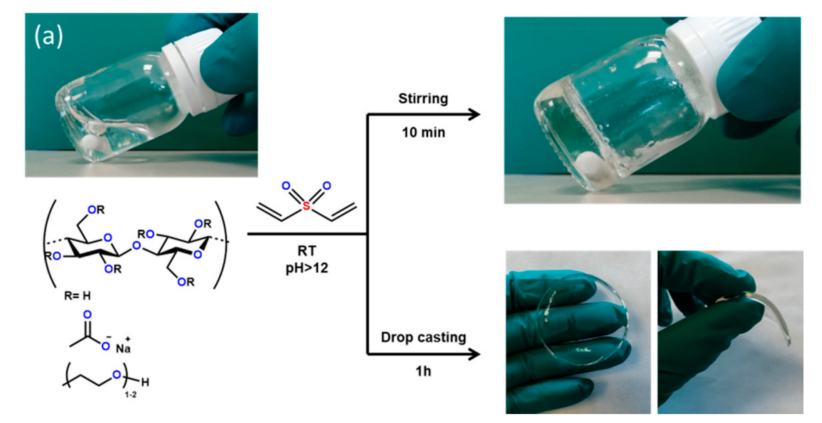

(b)

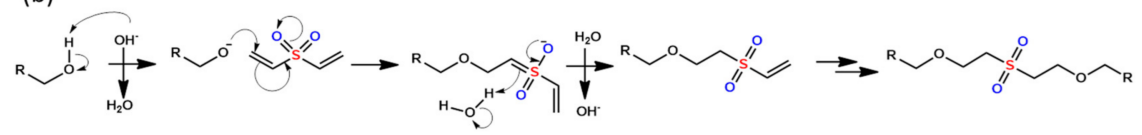

Figure 1. (a) Schematic representation of the synthesis of cellulose-based hydrogels (b) and crosslinking reaction mechanism. 
The effect of the cellulose derivatives' weight ratio (hydrogel composition) in the crosslinking reaction was investigated (Table 1). When HEC was used as the only cellulose source (CBH-1), the obtained material was a tough, solid gel that released water from its structure. In order to improve the water retention of $\mathrm{CMC}$, an anionic cellulose derivative was added to the formulation. The gels $\mathrm{CBH}-2, \mathrm{CBH}-3$ and $\mathrm{CBH}-4$, with an increased concentration of $\mathrm{CMC}$, were found to be softer gels that did not release a significant amount of water (Figure 2). In an attempt to have the maximum amount of ionic moieties in the gel matrix, the crosslinking reaction was tried with only $\mathrm{CMC}$ as the cellulose source, but no gel was formed (CBH-5 in Figure 2).

Table 1. Influence of the cellulose derivatives' weight ratios on the gel formation and appearance.

\begin{tabular}{cccccc}
\hline $\begin{array}{c}\text { Cellulose-Based } \\
\text { Hydrogels (CBH) ID }\end{array}$ & $\begin{array}{c}\text { Carboxymethyl } \\
\text { Cellulose (CMC) } \\
\text { Wt. \% }\end{array}$ & $\begin{array}{c}\text { Hydroxyethyl } \\
\text { Cellulose (HEC) } \\
\text { Wt. \% }\end{array}$ & $\begin{array}{c}\text { Divinyl } \\
\text { Sulfone (DVS) } \\
\text { Wt. \% }\end{array}$ & $\begin{array}{c}\text { KOH } \\
\mathbf{m M}\end{array}$ & Observation \\
\hline CBH-1 & 0 & 4 & & 20 & Gelled, release of water \\
CBH-2 & 1 & 3 & 2 & 20 & $\begin{array}{c}\text { Full gel formed, } \\
\text { no release of water }\end{array}$ \\
CBH-3 & 2 & 2 & & & Not gelled \\
CBH-4 & 3 & 0 & & & \\
CBH-5 & 4 & & &
\end{tabular}

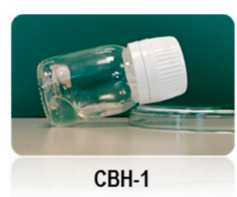

0 wt\% $\%$ CMC -4 wt\%HEC

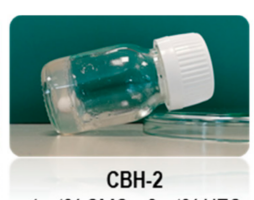

1 wt\% CMC -3 wt\%HEC

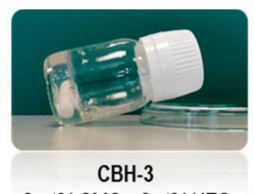

$2 w+\%$ CMC $-2 w t \% H E C$

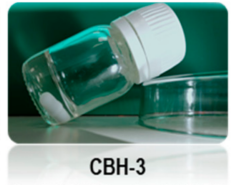

3 wt\% CMC -1 wt\%HEC

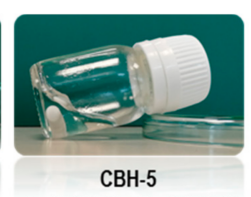

4 wt\% $\mathrm{CMC}-0 \mathrm{wt} \% \mathrm{HEC}$

Figure 2. Digital images of gel appearance as a function of the cellulose derivatives' weight ratio. $\mathrm{CBH}$ is the abbreviation for cellulose-based hydrogel; CMC for carboxymethyl cellulose and HEC for hydroxyethyl cellulose.

It has already been reported that CMC shows no reactivity towards DVS since the reactants of the $\mathrm{OH}^{-}$groups in position $\mathrm{C} 6$ are, to a large extent, replaced by carboxyl groups, and the other hydroxyl groups present in the cellulose backbone (C2 and C3) are sterically hindered $[28,29]$. This fact points out that, when both cellulose derivatives are present, only HEC takes part in the crosslinking reaction with DVS (Figure 1b). This process leads to a structure so-called the semi-interpenetrating polymer network (semi-IPN), where a linear polymer is imbibed in a tridimensional crosslinked network [6]. This structure enables combining the functionality of a linear polymer with the mechanical properties provided by the crosslinked material—in this case, the water retention ability of the CMC polymer with the gel forming ability of the HEC-DVS system.

The chemical characterization was performed over the hydrogel obtained with HEC as the only cellulose source in order to avoid signals from CMC that could interfere with the signals of the reaction. Figure 3 a displays the ${ }^{1} \mathrm{H}$ NMR spectra of DVS, HEC and the formed hydrogel (CBH-1). DVS spectra are characterized by the signal of the double bounds at 6.4 and $7.0 \mathrm{ppm}$ (blue and red circles, respectively). These signals are not present in $\mathrm{CBH}-1$ spectra. This result confirms the total consumption of DVS during the HEC crosslinking. Furthermore, CBH-1 spectra show new bands at 3.9 and $4.1 \mathrm{ppm}$ (orange and green circles, respectively), which are assigned to the protons bonded to the sulfonyl group. In contrast, the signals (3.6-3.8 ppm) from the HEC backbone remain unaltered (region marked by the blue line in Figure 3a), as demonstrated by the HEC spectra.

To further confirm the crosslinking reaction, ATR-FTIR spectra of HEC and CBH-1 (dried film of the hydrogel HEC-DVS) were measured (Figure 3b). The bands related to the HEC backbone, namely the O-H stretching vibration $\left(3500 \mathrm{~cm}^{-1}\right), \mathrm{C}-\mathrm{H}$ stretching vibration $\left(2950 \mathrm{~cm}^{-1}\right), \mathrm{C}-\mathrm{H}$ and O-H bending vibrations (1400-1100 $\mathrm{cm}^{-1}$ ) and the band related to the $\beta(1-4)$ glycosidic bond $\left(920 \mathrm{~cm}^{-1}\right)$, remain unaltered (red line) in the CBH-1 spectrum (black line) [30,31]. For CBH-1, a new broad band 
with a shoulder at $1310 \mathrm{~cm}^{-1}$ and the peak of the band at $1280 \mathrm{~cm}^{-1}$ appears. This band is assigned to the $\mathrm{S}=\mathrm{O}$ stretching vibration of the sulfone moiety and the ether bond (C-O-C) between HEC and DVS [32]. This confirms the successful reaction between DVS and HEC.
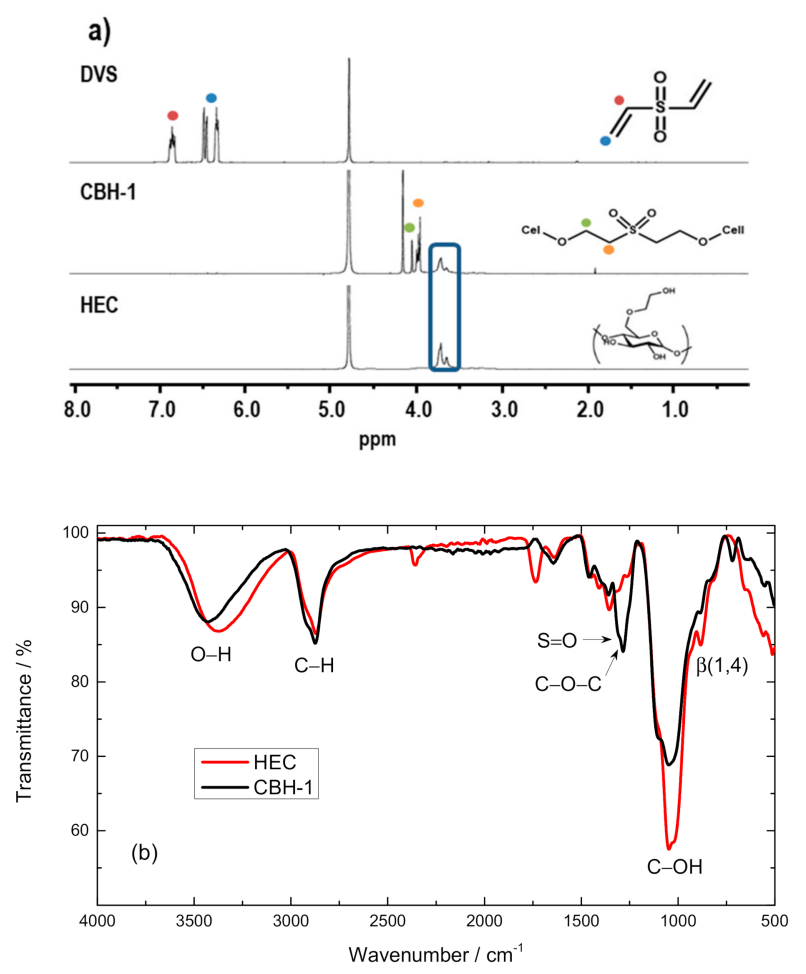

Figure 3. Characterization of the crosslinking reaction: (a) $\mathrm{H}^{1} \mathrm{NMR}$ spectra of divinyl sulfone (DVS) (top); CBH-1 (middle) and HEC (bottom); (b) spectra of HEC (red) and CBH-1 (black).

\subsection{Rheological Characterization}

The gel properties were studied by the small-amplitude oscillatory shear (SAOS) rheological technique. For these measurements, the preparation of the sample is essential [33]. If the hydrogel is prepared ex situ, when placed in the rheometer geometry, the structure might be stressed by the pressure of the plate, disturbing the results. Therefore, the samples were placed in their liquid state and gelled in situ to the parallel plates at room temperature. The protocol set by Morrison and coworkers establishes that firstly an approximated gel time has to be determined by performing a time sweep, where arbitrary values of strain and frequency are set [33]. Taking previous reports on CBH formed by the HEC-DVS system, a strain of $1 \%$ and frequency of $1 \mathrm{~Hz}$ were chosen [27]. Afterwards, the linear viscoelastic regime (LVE) and linear modulus plateau (LMP) were studied by strain and frequency sweeps. In this way, a systematic study of the effect of $\mathrm{KOH}$ concentration and HEC to DVS wt. \% ratio (Table 2) on the rheological properties of the hydrogels was performed.

The rheological characterization of hydrogel CBH-3 is displayed in Figure S1 as a representative study for every single gel investigated. The outcomes are summarized in Table 2 for all CBHs. Figure S1a illustrates the time sweep experiment, where initially the loss modulus ( $\mathrm{G}^{\prime \prime}$; dashed line) is above the storage modulus ( $\mathrm{G}^{\prime}$; solid line). This means that the sample has a viscous (liquid) behavior. The point when the $\mathrm{G}^{\prime}$ line crosses the $\mathrm{G}^{\prime \prime}$ line is assigned as the gelling time. For CBH-3, it was $12 \mathrm{~min}$. It is worth mentioning that the storage modulus continues to increase over a period of $80 \mathrm{~min}$. This suggests that the sol-gel transition happens at the beginning of the crosslinking reaction. Consequently, taking this information into account, the strain and frequency sweeps were performed after allowing the gel to react for $90 \mathrm{~min}$. 
Table 2. Dependence of gel time, storage modulus $\left(G^{\prime}\right)$, mesh size $(\xi)$ and ionic conductivity $(\sigma)$ on $\mathrm{KOH}$ concentration and HEC to DVS weight ratio.

\begin{tabular}{cccccccccc}
\hline \multirow{2}{*}{ Gel ID } & $\begin{array}{c}\text { CMC } \\
\text { wt. \% }\end{array}$ & $\begin{array}{c}\text { HEC } \\
\text { wt. \% }\end{array}$ & $\begin{array}{c}\text { DVS } \\
\text { wt. \% }\end{array}$ & $\begin{array}{c}\text { KOH } \\
\mathbf{m M}\end{array}$ & $\begin{array}{c}\text { Gel Time } \\
\text { min }\end{array}$ & $\begin{array}{c}\mathbf{G}^{\prime} \\
\mathbf{P a}\end{array}$ & $\begin{array}{c}\xi \\
\text { nm }\end{array}$ & \multicolumn{2}{c}{$\mathbf{\sigma}(\mathbf{m S} / \mathbf{c m})$} \\
\hline CBH-6 & & & & 10 & 45 & 1100 & 15.52 & 5.2 & 0.82 \\
CBH-3 & \multirow{2}{*}{2} & 2 & 2 & 20 & 12 & 3100 & 10.99 & 4.7 & 1.63 \\
CBH-7 & & & & 30 & 8.3 & 7300 & 8.26 & 5.8 & 2.41 \\
CBH-8 & & & & 40 & 7.4 & 9100 & 7.67 & 6.0 & 3.25 \\
CBH-9 & \multirow{2}{*}{2} & 1 & 3 & 20 & 21 & 1100 & 15.52 & 5.0 & 1.63 \\
CBH-10 & & 3 & 1 & & 13 & 3500 & 10.55 & 3.3 & \\
\hline
\end{tabular}

The viscoelastic behavior was studied by applying a strain sweep at a frequency of $1 \mathrm{~Hz}$ (Figure S1b). The LVE region covers from $0.01 \%$ to $20 \%$ of the strain, where the storage modulus $\left(\mathrm{G}^{\prime}\right)$ suffers a deviation from the linearity. This indicates that the sample starts to flow, suggesting that the tridimensional network responsible of the elastic behavior started to break.

Additionally, the frequency sweep was performed at a strain of $1 \%$ in a range of 0.001 to $100 \mathrm{~Hz}$ (Figure S1c). CBH-3 presents an LMP up to $50 \mathrm{~Hz}$. The results point out that the time sweep performed at $1 \%$ of strain and $1 \mathrm{~Hz}$ is within the LVE and LMP ranges. These results reinforce that the value obtained for the sol-gel transition can be taken as valid. Therefore, the sol-gel transition values were then established for characterizing all the gels (gel time in Table 2).

The dependence of the gel time (sol-gel transition) on the KOH concentration and HEC-DVS wt. \% ratio is displayed in Figure $4 \mathrm{a}, \mathrm{b}$, respectively. As noticed, increasing the $\mathrm{KOH}$ concentration provokes a faster sol-gel transition, as shown in Figure 4a and reported in Table 2. It is understood as an increment in the crosslinking kinetics induced by the higher concentration of alkoxy anions when the $\mathrm{KOH}$ concentration rises. This may lead to a higher reactivity of HEC. In contrast, when the ratio HEC-DVS increases at the same $\mathrm{KOH}$ concentration, it results in a lower gel time (viz., $21 \mathrm{~min}$ for CBH-9, 12 min for CHB-3 and 13 min for CBH-10). This faster crosslinking kinetics is then associated with the higher HEC content as the reactive compound.

Additionally, at a low-frequency range, the constant modulus $\left(\mathrm{G}^{\prime}\right)$ can be correlated with the mesh size. Thus, through the simple rubber elasticity theory (Equation (1)), it was calculated for each hydrogel (Table 2) [34]:

$$
\xi=\sqrt[3]{\frac{k_{B} T}{G^{\prime}}}
$$

where $\xi$ is the mesh size, $k_{B}$ is the Boltzmann constant and $T$ is the temperature.
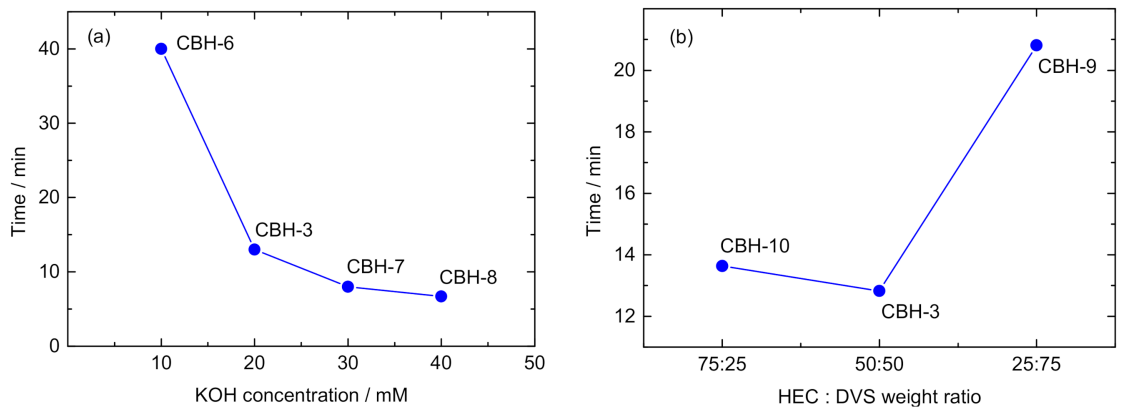

Figure 4. Sol-gel transition of hydrogels depending on (a) concentration of $\mathrm{KOH}$ and (b) HEC-DVS weight ratio.

After equilibration of the crosslinking reaction, the hydrogels were subjected to strain and frequency sweeps (Figures S2 and S3). As summarized in Table 2, the modulus ( $\mathrm{G}^{\prime}$ ) of the hydrogels and the mesh sizes $(\xi)$ show a strong dependency on the reaction conditions. As reported, when the $\mathrm{KOH}$ concentration is, e.g., four times higher (from 10 to $40 \mathrm{mM}$ ), $\mathrm{G}^{\prime}$ increases almost one order 
of magnitude (from 1100 for CBH-6 to 9100 Pa for CBH-8). Furthermore, the increment of $\mathrm{KOH}$ concentration promotes a higher crosslinking density as represented by the lower mesh size values. As previously stated, the higher concentration of hydroxide $\left(\mathrm{OH}^{-}\right)$in the aqueous media promotes a higher alkoxy anion amount in HEC, leading to higher crosslinking points in the macromolecular structure. Similar behavior can be observed when increasing the HEC-DVS ratio, i.e., higher modulus and lower mesh size, indicating a higher crosslinking density. In contrast, as shown, when the content of HEC in the gel is lower (i.e., 1 wt. \% in CBH-9), the concentration of the reactant decreases. It leads to a low crosslinking density and therefore a lower modulus $\left(\mathrm{G}^{\prime}=1100 \mathrm{~Pa}\right)$ and higher mesh size $(\xi=15.52 \mathrm{~nm})$.

The viscoelastic properties of the CBHs are given by the behavior of the lineal viscoelastic regime (LVE) and the linear modulus plateau (LMP). All the hydrogels show a very similar LMP of around $50 \mathrm{~Hz}$ (Figures S2b and S3b). However, the LVE has a strong dependence on the $\mathrm{KOH}$ concentration and hence on the crosslinking density. When the hydrogel is highly crosslinked (viz., CBH-7 and CBH-8; Table 2), the viscoelastic response is lower (LVE of about $13 \%$ strain) due to a more rigid structure (Figure S2a). In contrast, at lower $\mathrm{KOH}$ concentration (lower crosslinking density), the ability of the tridimensional network to absorb stress (strain) increases. The latter is translated into higher LVE values for CBH-3 (38\% strain) and CBH-6 (80\% strain). Interestingly, the LVE regime is very similar for $\mathrm{CBH}-9$ and $\mathrm{CBH}-10$, suggesting that the variation in the HEC to DVS ratio has little impact in the viscoelastic properties (Figure S3a).

This comprehensive characterization of the rheological properties of cellulose-based hydrogels reveals that by tuning the formulation, parameters such as the modulus, sol-gel transition and viscoelastic properties can be adjusted. This feature may allow choosing the desired parameters of the selected processing techniques, such as printing (screen, ink-jet, 3D) or coating (dip, spin or knife) methods for a given application.

\subsection{Ionic Conductivity}

Once the crosslinking reaction and the mechanical properties were characterized, the other main feature of the gel electrolytes, namely ionic conductivity, was characterized. Similarly to the rheological measurements, the hydrogels were synthesized in situ in a coin cell for their characterization. The values of ionic conductivities are listed in Table 2. The gels possess higher ionic conductivities than their corresponding aqueous media, mainly due to the presence of a higher amount of mobile ions, namely the $\mathrm{Na}^{+}$cations from the CMC. This fact points out that the ionic nature of CMC has two effects on hydrogels: on one hand, it enhances the water retention, and on the other hand, it increases the ionic conductivity of the hydrogels.

In the gels $\mathrm{CBH}-6, \mathrm{CBH}-7$ and $\mathrm{CBH}-8$, the $\mathrm{KOH}$ aqueous solutions show an increasing trend of ionic conductivity with the concentration. However, this has little impact on the conductivity of the gels, where the values remain very similar (between 5 and $6 \mathrm{mS} \mathrm{cm}^{-1}$ ). In the case of CBH-9 and 10, a decrease in the ionic conductivity is observed, although the concentration of $\mathrm{CMC}$ and $\mathrm{KOH}$ remains constant. This behavior can be correlated with the results obtained in the rheological measurements (Section 3.2). In the case of the increasing the $\mathrm{KOH}$ concentration, although the ionic conductivity of the solution is higher, the decrease in the mesh size due to the higher crosslinking density hinders the mobility of the ions through the structure. When increasing the HEC-DVS ratio, the mesh size decreases with a consequent drop in the ionic conductivity.

Finally, the viability of this cellulose-based hydrogel as electrolytes in electrochemical devices was assessed. As a proof of concept, electrochromic displays (ECDs) and primary printed $\mathrm{Zn} / \mathrm{MnO}_{2}$ batteries were chosen.

\subsection{Electrochromic Devices (ECDs)}

Among a variety of electrochromic (EC) device configurations, they can be broadly divided into two major groups: (1) layered- and (2) all-in-one-type configurations. The layered type refers to the 
ECD architecture wherein the chromophore is deposited on or attached to the working electrode and the electrolyte is incorporated as a discrete layer [35-38]. The all-in-one type describes a less complex device architecture in which all electroactive materials (i.e., EC materials and the redox mediators) are dissolved in the electrolyte, and the resulting EC mixture (single layer) is sandwiched between two electrode substrates in a symmetric device configuration (e.g., glass/TCO/EC mixture/TCO/glass). Apart from the predictable advantages of the all-in-one configuration (simpler assembly process, easier to industrialize), it may also exhibit other strengths, such as exceptional versatility, enhanced durability and suitability for flexible substrates [39]. In addition, the employment of these all-in-one device architectures together with gel electrolytes has been proven to stabilize some chemical substances involved in EC systems, enhancing the chromatic diversity of ECDs. In this context, the development of cellulose-based hydrogel electrolytes suitable for all-in-one ECDs may be the more environmental approach to maintain all these exceptional features [40,41]. However, the main reported devices employed layered-type configurations using rigid-glass substrates [42-48]. In this context, it is worth to point out that the ECDs comprising cellulose hydrogel electrolytes reported herein are based on all-in-one configurations employing flexible substrates (ITO/PET).

An optimized cellulose-based EC hydrogel: $20 \mathrm{mM}$ of EtVio as the EC material and $6 \mathrm{mM}$ of Ferro/Ferri as the redox mediator, was assembled in all-in-one architecture with the $\mathrm{CBH}-3$ composition (Figure 5a). It is worth mentioning that the commercial DVS is stabilized with hydroquinone (HQ). In order to avoid the possible effect of HQ on the electrochromic behavior, DVS was purified by passing it through the inhibitor remover column. Aiming to promote a concentration gradient of the viologen molecules on the cathode/electrolyte interface, devices were exposed to a suitable cathodic potential for a longer time than that required for the sol-gel transition to occur (i.e., $-1.0 \mathrm{~V}$ for $15 \mathrm{~min}$.). Afterward, the EC performance of these ECDs was conveniently evaluated to assess the suitability of the cellulose hydrogel reported herein as a potential electrolyte.
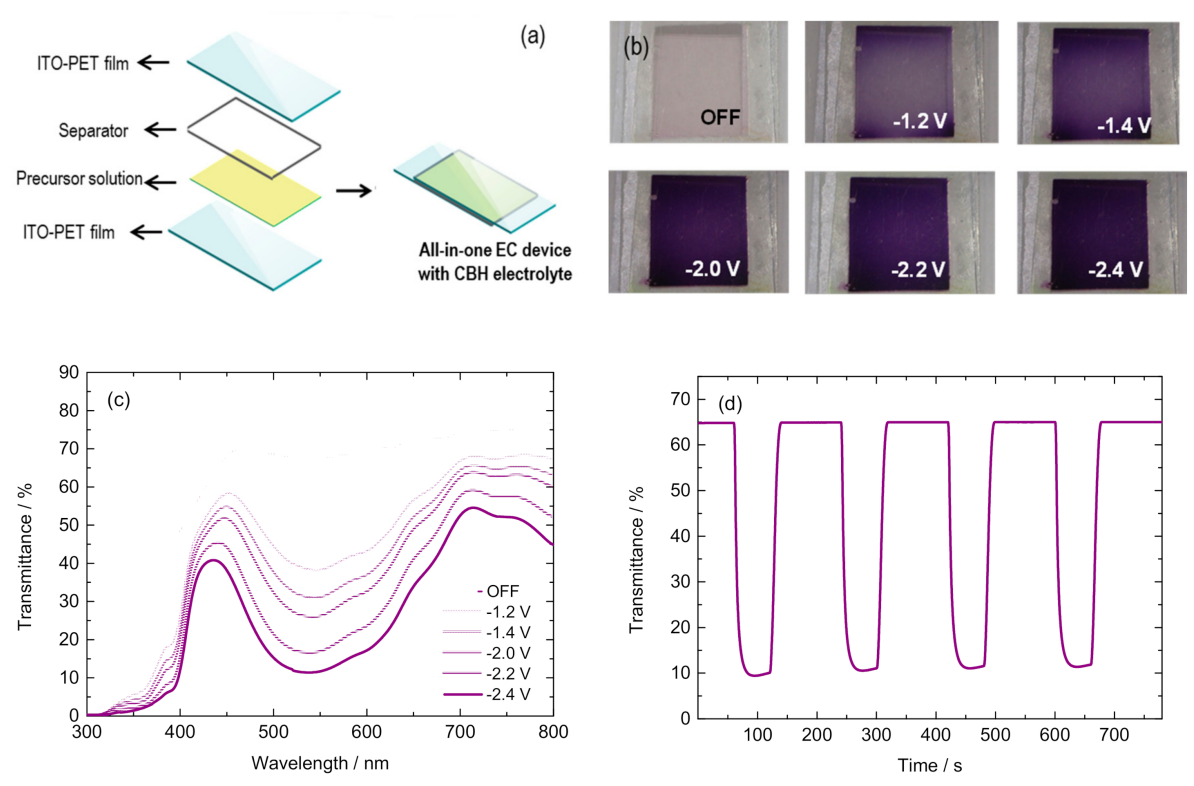

Figure 5. Electrochromic performance of cellulose-based hydrogels (CBHs): (a) schematic representation of the all-in-one electrochromic (EC) device with the flexible poly(ethylene terephtalate) coated with indium tin oxide (ITO-PET); (b) pictures at bleached state (OFF) and upon applying different cathodic potentials (from -2.4 to $-1.2 \mathrm{~V}$ ); (c) transmittance spectra at bleached state (OFF) and upon applying different cathodic potentials (from -2.4 to $-1.2 \mathrm{~V}$ ); (d) transmittance changes (at $550 \mathrm{~nm}$ ) vs. time with square wave potential steps between bleached $(0 \mathrm{~V}$ for $120 \mathrm{~s})$ and colored state $(-2.4 \mathrm{~V}$ for $60 \mathrm{~s})$.

Two main parameters to evaluate the electrochromic behavior of EC devices are the level of coloration and the transmittance changes between the colored and bleached states. The devices showed 
a transparent colorless off-state and acquired a weak bluish coloration upon applying $-1.2 \mathrm{~V}$ (Figure $5 \mathrm{~b}$ ). As the cathodic potential increased, the transmittance level of the device diminished, providing ECDs with higher levels of coloration. The level of coloration of the devices was evaluated through UV-visible transmittance spectra for different applied potentials (Figure 5c). The percentage of transmittance $(\% \mathrm{~T})$ at the maximum contrast wavelength $(550 \mathrm{~nm})$ reached a value of $12 \%$ when the device was exposed to $-2.4 \mathrm{~V}$ (Table S1). The transmittance changes $(\Delta \% \mathrm{~T})$, defined as the difference between the transmittance in the bleached state and that obtained in the colored state, ranged from $29.4 \%$ to $55.8 \%$ for -1.2 and $-2.4 \mathrm{~V}$ applied potentials, respectively, thus providing ECDs with modulated levels of coloration.

With regard to the colorations displayed by the ECDs at both colorless off-state and colored state $(-2.4 \mathrm{~V})$, an unequivocal interpretation of them was numerically determined through the transmittance profiles of the ECDs and using a spectrophotometric method previously reported (Table S2) $[49,50]$. These data confirmed the absence of color ( $\mathrm{a}^{*}$ and $\mathrm{b}^{*}$ chromaticity coordinates very close to 0 value) and the excellent transparency ( $\left.{ }^{*} \mathrm{~L} 86\right)$ of the ECDs at off-state. Upon applying $-2.4 \mathrm{~V}$ cathodic potential, color coordinates revealed a significant decrease in the lightness $\left({ }^{*} \mathrm{~L} 46\right)$, in agreement with the high $\Delta \% \mathrm{~T}$ obtained for this voltage. Noteworthy variation was also observed for chromaticity coordinates at the stated cathodic potential. Thus, $\mathrm{a}^{*}$ and $\mathrm{b}^{*}$ color coordinates acquired 32 and -31 values, respectively, revealing red and blue characters of the resultant purple-colored state. This coloration observed in ECDs based on alkyl viologens, such as EtVio employed herein, is attributed to the well-studied phenomenon of the radical cation monomer (blue) and its dimer formation (red), more likely to occur when using aqueous electrolytic systems [26,51].

Another key parameter for assessing the electrochromic behavior of EC devices is the switching time, denoting the time required to observe the transition between the colored and bleached states. The devices were exposed long enough to square-wave potential steps between bleached $(0 \mathrm{~V})$ and colored states $(-2.4 \mathrm{~V})$ while the corresponding transmittance changes were being recorded in the spectrophotometer over time at a fixed wavelength of $550 \mathrm{~nm}$ (Figure $5 \mathrm{~d}$ ). These studies revealed switching times of $11 \mathrm{~s}$ for both coloring $(\mathrm{tc})$ and bleaching processes $(\mathrm{tb})$, estimated as the time required to reach $90 \%$ of the total $\Delta \% \mathrm{~T}$ for the colored and bleached steps.

With regard to the power efficiency of the devices, it is usually quantified through their color efficiencies $(\eta)$. The latter parameter, correlated with the electrode area, is defined as the change in optical density during the redox process at a given wavelength divided by the injected/ejected charge [45]. The ECDs based on the cellulose hydrogel reported herein exhibited color efficiencies of 122 and $218 \mathrm{~cm}^{2} \mathrm{C}^{-1}$ for coloring $(\eta \mathrm{c})$ and bleaching processes $(\eta \mathrm{b})$, respectively $(\lambda=550 \mathrm{~nm})$.

In order to assess the flexibility of the devices and therefore their feasibility to be adapted to non-flat surfaces, the ECDs were exposed to bending tests. The coloration of the devices remained homogeneous during the bending process due to the self-standing character of the electrolyte that guarantees a regular distribution of it throughout the device area (Figure S4a). Further bending studies confirmed the stability of the ECDs, with no decay of their coloration or $\Delta \% \mathrm{~T}$ and no visual signs of deterioration after 50 cycles of bending (Figure S4b,c and Table S3).

When comparing these results with the little available reports on other all-in-one EC systems based on viologens and comprising cellulose derivative electrolytes, some conclusions can be drawn. The maximum transmittance variation achieved for the flexible EC system reported in the present work (i.e., 55.8\%) is in the range of that obtained for rigid-glass devices and overruns that reported for flexible plastic substrates. The switching times of the EC system described herein were in the range of the latter, while the color efficiencies were close to the former [47,52]. These results prove that the room-temperature self-standing cellulose hydrogel employed in the present work may be a potential electrolyte for all-in-one ECDs. 


\subsection{Batteries}

Nowadays, among others, devices like wireless sensors, smart labels, medical strips, printed electronics for different applications such as the Internet of Things (IoT) and wearable electronics need power in the range of microwatts $(\mu \mathrm{W})$ to milliwatts $(\mathrm{mW})$, and capacities from microamp-hours $(\mu \mathrm{Ah})$ to hundreds of milliamp-hours (mAh), depending on the final application. This need has driven the development of thin, small, low-cost and environmentally friendly batteries as a power source. Battery manufactures look for simplifying the process to achieve lower cost, quality and mass production. Furthermore, if manufacturing includes a low-temperature process, it will enable the use of flexible substrates and more environmentally friendly materials like, e.g., paper. In that regard, printing technologies seem to be an attractive alternative for manufacturing such type of batteries, promising a cheap mass production while the need for the customization or design of the batteries to meet the specific requirements of the final application is assured. Besides, printing technologies enable advanced large-scale manufacturing processes of batteries, such as printing into integrated platforms and/or onto soft substrates for flexible and stretchable devices $[53,54]$

Aqueous batteries are an attractive option as sustainable and safe technologies for energy storage in several applications, as mentioned above. Consequently, zinc-based battery technologies show up as promising candidates thanks to the electrochemical properties and environmental friendliness of zinc [55]. On the other hand, the use of hydrogel electrolytes has boosted the research of these systems in flexible and/or printed applications [56]. However, the main used materials for those implemented in hydrogel electrolyte synthesis rely on synthetic polymers such as poly(vinyl alcohol) (PVA), poly(acrylic acid) (PAA) and/or poly(acrylamide) (PAM) [57]. In order to move towards a more sustainable system, the use of cellulose-based hydrogels as electrolytes is an attractive alternative.

Taking into account the aspects mentioned above, this section focuses on a primary (not rechargeable) printed battery using traditional zinc/manganese dioxide chemistry manufactured and kindly provided by Varta Microbattery $\mathrm{GmbH}$. With this battery, the here proposed hydrogel electrolyte approach will be evaluated as a function of the battery performance. Figure S5 illustrates a schematic representation of the battery printed on a paper substrate. The battery has a so-called co-planar (also known as side-by-side) configuration. The black square represents the positive electrode composed of carbon and $\mathrm{MnO}_{2}$ and the gray square exemplifies the negative electrode based on zinc. The commonly used electrolytes are a solution of zinc chloride $\left(\mathrm{ZnCl}_{2}\right)$ or $\mathrm{KOH}$ from which the battery is known as a zinc-chloride or alkaline battery, respectively. The conventional and commercial available battery format of this chemistry is usually recommended for low-drain devices since they are a very reliable source of power on both continuous and intermittent discharges and when cost is an important consideration. This battery chemistry has usually a nominal voltage of about $1.5 \mathrm{~V}$.

Figure 6a represents the sequence implemented for casting (coating mask) the hydrogel electrolyte and subsequently sealing (sealing mask) the battery. The hydrogel CBH-3 $(20 \mathrm{mM} \mathrm{KOH})$ was casted upon the electrodes, left to react for about $90 \mathrm{~min}$ and sealed (see Section 3.2) before electrochemically assessing the battery. The open circuit potential (OCV) for this battery was around $1.26 \mathrm{~V}$, which is slightly lower than the usually reported value for alkaline batteries (i.e., $1.43 \mathrm{~V}$ for $\mathrm{Zn}(\mathrm{s})+2 \mathrm{MnO}_{2}(\mathrm{~s})$ $\rightarrow \mathrm{ZnO}(\mathrm{s})+\mathrm{Mn}_{2} \mathrm{O}_{3}(\mathrm{~s})$ ). This deviation could be due to side reactions happening on the $\mathrm{Zn}$ surface promoting the formation of zincates like $\left[\mathrm{Zn}(\mathrm{OH})_{3}\right]^{-}$and $\left[\mathrm{Zn}(\mathrm{OH})_{4}\right]^{2-}$ which have an equilibrium potential about $-1.15 \mathrm{~V}$ and $-1.199 \mathrm{~V}$, respectively. At the positive electrode, $\mathrm{MnO}_{2}$ is usually in equilibrium with $\mathrm{Mn}_{2} \mathrm{O}_{3}\left(\mathrm{E}^{\mathrm{o}}=0.15 \mathrm{~V}\right)$. Thus, the overall cell potential might be expected to be around 1.3 and 1.35 V. Figure S6 shows the discharge profile of CBH-3 at two discharge currents (50 and $100 \mu \mathrm{A})$. The curves fall with a very steep slope that can be assigned to the low rate capability of the battery with CBH-3. It could be assigned to the high resistance (113 Ohm from Figure S7) and/or to the fast passivation of the zinc surface in this configuration where insoluble $\mathrm{ZnO}(\mathrm{s})$ may occur, preventing the maximal utilization of the zinc electrode. The battery provided in both cases about $90 \mu \mathrm{Ah}$ of capacity up to $1.0 \mathrm{~V}$. The latter could be also assigned to the limited accessibility of the active materials (zinc and manganese dioxide) to the in situ generated hydrogel electrolyte. 
In order to access the versatility of implementing hydrogel electrolytes and to evaluate the electrochemical performance of the battery, another electrolyte system based on $\mathrm{ZnCl}_{2}$ was introduced to the $\mathrm{CBH}$. Initially the addition of $\mathrm{Zn}$ salt was tried by the one-pot approach, similarly to the previous experiments of ECDs. However, the presence of $\mathrm{Zn}$ cations was not compatible with this system (Figure S8a). On one hand, zinc reacted with the hydroxide present in the media, forming oxides. Consequently, this reaction consumes $\mathrm{OH}^{-}$, provoking a decrease in the $\mathrm{pH}$. On the other hand, a phase separation and precipitation of the system was observed, driven by the ionic interaction of the divalent $\mathrm{Zn}^{2+}$ cations with the negatively charged CMC (Figure S8b). Alternatively, in order to obtain a hydrogel containing the $\mathrm{ZnCl}_{2}$ electrolyte, it took advantage of the superabsorbent properties of the cellulose-based hydrogels [29]. In this regard, a precursor solution of CHB-3 was casted onto a glass substrate and covered with a Petri dish in order to avoid a fast evaporation of DVS for $90 \mathrm{~min}$. Then, the formed self-standing hydrogel was dried under mild conditions in an oven at $30^{\circ} \mathrm{C}$ until constant weight. Afterwards, the resulting film was immersed into a solution of $1 \mathrm{M} \mathrm{ZnCl}_{2}$. The increase in weight was monitored over time, showing a maximum electrolyte uptake of $70 \mathrm{wt}$. $\%$ of the dried gel weight after $180 \mathrm{~min}$ (Figure 6b). It is worth mentioning that the hydrogel membrane maintained the mechanical stability and shape after the swelling process (Figure S9).

(a)
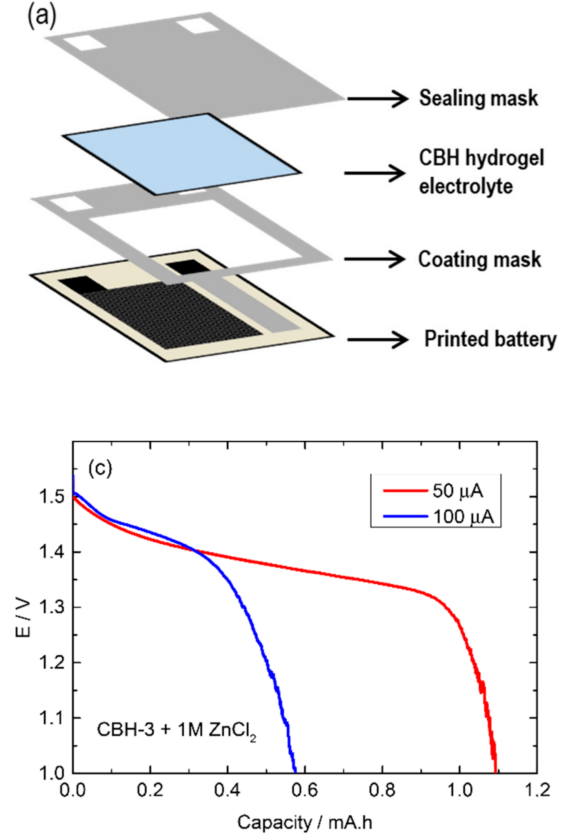
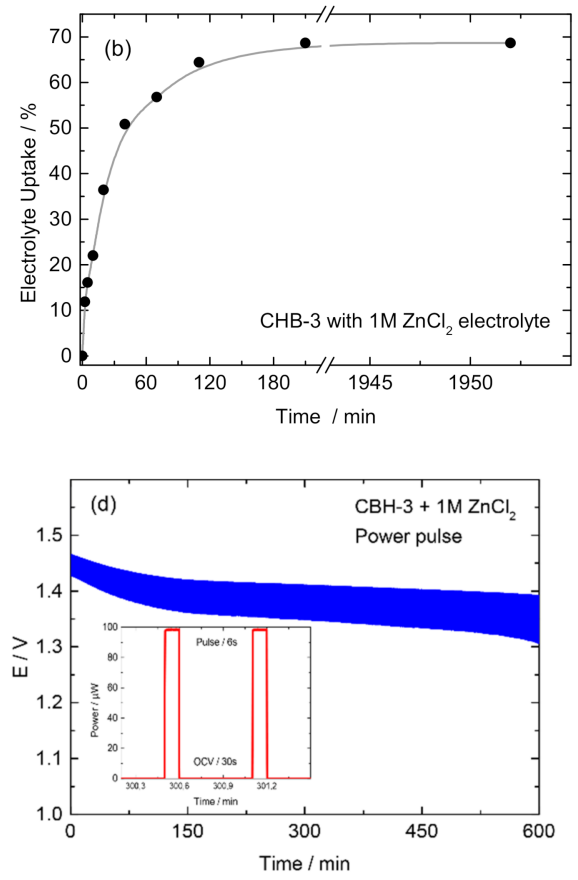

Figure 6. (a) Schematic representation of the coating procedure of cellulose-based hydrogel upon printed battery; (b) swelling behavior of $\mathrm{CBH}$ with $1 \mathrm{M} \mathrm{ZnCl}_{2}$ electrolyte; (c) galvanostatic discharge curves of the printed battery with $\mathrm{CBH}-3$ swelled in $1 \mathrm{M} \mathrm{ZnCl}_{2}$; (d) intermittent discharge profile via power pulses (6 s: $100 \mu \mathrm{W} ; 30 \mathrm{~s}$ : open circuit potential (OCV)) of the battery with CBH-3 swelled in $1 \mathrm{M} \mathrm{ZnCl}_{2}$.

After setting the swelling procedure of $\mathrm{CBH}-3$ with the $\mathrm{ZnCl}_{2}$ solution, $\mathrm{CBH}-3$ was coated upon the battery. After film drying, it was determined that the weight of the cellulose-based film needed to cover the whole battery $\left(\sim 14 \mathrm{~cm}^{2}\right)$ was as low as $100 \mathrm{mg}\left(\mathrm{ca} .7 \mathrm{mg} \mathrm{cm}^{-2}\right)$. A given volume of $1 \mathrm{M}$ $\mathrm{ZnCl}_{2}$ solution was added to the dried film, ensuring the wetting of the whole area of the battery, and then sealed (Figure 6a). In order to monitor the swelling of the hydrogel, the OCV of the battery was measured over time until a maximum of $1.52 \mathrm{~V}$ was achieved after $30 \mathrm{~min}$. The battery cells with CBH-3 swelled in $\mathrm{ZnCl}_{2}$ were discharged at a constant current of 50 and $100 \mu \mathrm{A}$ (Figure 6c). As noticed, up to $1.0 \mathrm{~V}$ (cut-off voltage), the battery delivered a nominal capacity as high as $1100 \mu \mathrm{Ah}$ (viz., $11.31 \mathrm{mAh} \mathrm{g}^{-1} \mathrm{Zn} ; 0.08 \mathrm{mAh} \mathrm{cm}^{-2} ; 5.67 \mathrm{Ah} \mathrm{cm}^{-3}$ ) at $50 \mu \mathrm{A}$. This value is more than one order 
of magnitude in comparison to that for the $\mathrm{CBH}-3$ electrolyte. This reflects that the electrochemical conversion of the zinc surface is more efficient as long as the active surface of the metal is exposed properly to the electrolyte which is achieved with the use of the swelled CBH-3 film. Thus, the difference in the capacity can be assigned to the limited contact of the active material with the $\mathrm{CBH}-3$ electrolyte. Furthermore, due to the mild acid $\mathrm{pH}$ (5-6) of the hydrogel electrolyte with $\mathrm{ZnCl}_{2}$, the zinc undergoes a conversion to $\mathrm{Zn}^{2+}$ without the formation of any passivation layer upon the metal surface. The overall capacity delivered by the battery coated with the hydrogel is lower (37\% less) than that for the battery discharged using the liquid $1 \mathrm{M} \mathrm{ZnCl}_{2}$ electrolyte (i.e., $1740 \mu \mathrm{Ah}$ in Figure S10). Nevertheless, it is worth mentioning that the voltage profiles for both are very similar. This reveals that the battery coated with the CBH-3 hydrogel swelled in $1 \mathrm{M} \mathrm{ZnCl}_{2}$ can provide the required power demanded by, e.g., smart labels or point-of-care devices.

As mentioned above, some IoT devices require power in the range of microwatts in an intermittent manner, thus the printed battery coated with $\mathrm{CBH}-3$ swelled in $\mathrm{ZnCl}_{2}$ was evaluated under such conditions by applying an intermittent discharge protocol demanding, for $6 \mathrm{~s}$, a power of $100 \mu \mathrm{W}$ for every $30 \mathrm{~s}$ (Figure 6d). As shown in Figure 6d, the battery was able to deliver about 1400 times the required power before reaching the cut-off voltage of $1.0 \mathrm{~V}$. These results prove that the room-temperature self-standing cellulose hydrogel could be implemented in power supply devices by adjusting its properties accordingly to the application of the device.

\section{Conclusions}

The present work points out the potential of cellulose-based hydrogels $(\mathrm{CBH})$ as electrolytes for electrochemical devices. The synthesis pathway involved a well-known method to crosslink cellulose derivatives in aqueous media with divinyl sulfone (DVS). The gels were formed through a semi-IPN structure where the 3D network was formed by crosslinked hydroxyethyl cellulose (HEC) and DVS, including carboxymethyl cellulose (CMC) to enhance the water retention of the gel owing to its ionic nature. The systematic rheological characterization revealed that the gelling time, the modulus and the viscoelastic behavior of hydrogels could be easily varied by simply choosing the proper $\mathrm{KOH}$ concentration or HEC-DVS ratio. The gels showed ionic conductivities as high as $6 \mathrm{mS} \mathrm{cm}^{-1}$.

As a proof of concept, the potential of these $\mathrm{CBHs}$ as electrolytes for electrochemical devices like electrochromic (EC) devices and batteries was assessed. On one hand, benefiting from the reaction conditions, ECDs with an all-in-one configuration employing flexible substrates were assembled, providing high transmittance changes (i.e., $\Delta \% \mathrm{~T}=55.8 \%$ ), suitable switching times (ca. $11 \mathrm{~s}$ ) and appropriate color efficiencies (about $218 \mathrm{~cm}^{2} \mathrm{C}^{-1}$ ), as well as proving the flexibility of the device thanks to the mechanical properties of the hydrogel. On the other hand, CBHs were used as electrolytes for printed batteries based on $\mathrm{Zn} / \mathrm{MnO}_{2}$ chemistry. Taking the advantage of the swelling ability of this hydrogel, the electrolyte was tuned to the battery needs. The printed battery showed a usual discharge profile for this type of battery chemistry and delivered a capacity as high as $1100 \mu \mathrm{Ah}\left(11 \mathrm{mAh} \mathrm{g}^{-1} \mathrm{Zn}\right.$; $0.08 \mathrm{mAh} \mathrm{cm}^{-2} ; 7.7 \mathrm{Ah} \mathrm{cm}^{-3}$ ) at $50 \mu \mathrm{A}$. These results allow demonstrating the feasibility and versatility of cellulose-based hydrogels as suitable, less toxic base electrolytes for electrochemical devices to be implemented in, e.g., smart labels, wearable electronics and wireless sensors. Thus, this study aims to promote further research on the use of well-known hydrogel systems based on biomaterials for more sustainable and cost-effective advanced applications.

Supplementary Materials: The following are available online at http://www.mdpi.com/2073-4360/12/11/2686/s1, Figure S1: Rheological characterization of $\mathrm{CBH}-3$. Figure S2: Rheological characterization of $\mathrm{CBH}$ versus $\mathrm{KOH}$ concentration. Figure S3: Rheological characterization of CBH versus the HEC-DVS ratio. Figure S4: Assessment of the feasibility of the $\mathrm{CBH}$ for flexible ECDs. Figure S5: Schematic representation of a printed Zinc/MnO2 battery. Figure S6: Galvanostatic discharge curves of printed battery with $\mathrm{CBH}-3$ electrolyte. Figure S7: Electrochemical spectroscopy impedance (Nyquist plots) of CHB-3 and $1 \mathrm{M} \mathrm{ZnCl} 2$ swelled CBH-3 electrolytes. Figure S8: Digital photographs of the effect of the addition of $\mathrm{ZnCl} 2(1 \mathrm{M})$ to $2 \mathrm{wt}$. \% of CMC (left) and to $20 \mathrm{mM}$ of $\mathrm{KOH}$ (right). Figure S9: Digital photographs of CBH-3 membranes. Figure S10: Galvanostatic discharge curve at $50 \mu \mathrm{A}$ of printed battery with a Whatman separator soaked in $1 \mathrm{M} \mathrm{ZnCl2} \mathrm{electrolyte.} \mathrm{Table} \mathrm{S1:} \mathrm{Transmittance} \mathrm{( \% )}$ at $550 \mathrm{~nm}$ and transmittance changes $(\Delta \% \mathrm{~T})$ of ECDs comprising optimized self-standing cellulose-based EC 
hydrogel at different applied potentials. Table S2: Color coordinates of ECDs comprising optimized self-standing cellulose-based EC hydrogel at bleached (off) and colored states $(-2.4 \mathrm{~V})$. Table S3: Bending test of flexible ECDs: transmittance $(\%)$ at $550 \mathrm{~nm}$ and transmittance changes $(\Delta \% \mathrm{~T})$ of flexible ECDs comprising optimized cellulose-based hydrogel before and after bending test (50 cyles).

Author Contributions: Conceptualization, I.G. and L.C.C.; methodology, I.G. and L.C.C.; investigation, I.G., L.C.C. and Y.A.; writing — original draft preparation, I.G. and L.C.C.; writing, Y.A.; review and editing, J.A.B., A.V. and L.C.C. All authors have read and agreed to the published version of the manuscript.

Funding: This project has received funding from the European Union's Horizon 2020 research and innovation programme under grant agreement No 760876 (INNPAPER).

Acknowledgments: Authors acknowledge Varta Microbattery $\mathrm{GmbH}$ for supplying the paper-based printed batteries in the frame of INNPAPER project.

Conflicts of Interest: The authors declare no conflict of interest. The funders had no role in the design of the study; in the collection, analyses, or interpretation of data; in the writing of the manuscript, or in the decision to publish the results.

\section{References}

1. Jeerapan, I.; Poorahong, S. Review-Flexible and Stretchable Electrochemical Sensing Systems: Materials, Energy Sources, and Integrations. J. Electrochem. Soc. 2020, 167, 037573. [CrossRef]

2. Song, W.; Yoo, S.; Song, G.; Lee, S.; Kong, M.; Rim, J.; Jeong, U.; Park, S. Recent Progress in Stretchable Batteries for Wearable Electronics. Batter. Supercaps 2019, 2, 181-199. [CrossRef]

3. Wang, Z.; Li, H.; Tang, Z.; Liu, Z.; Ruan, Z.; Ma, L.; Yang, Q.; Wang, D.; Zhi, C. Hydrogel Electrolytes for Flexible Aqueous Energy Storage Devices. Adv. Funct. Mat. 2018, 28, 1804560. [CrossRef]

4. Choudhury, N.A.; Sampath, S.; Shukla, A.K. Hydrogel-Polymer Electrolytes for Electrochemical Capacitors: An Overview. Energy Environ. Sci. 2009, 2, 55-67. [CrossRef]

5. Ahmed, E.M. Hydrogel: Preparation, Characterization, and Applications: A Review. J. Adv. Res. 2015, 6, 105-121. [CrossRef]

6. Ullah, F.; Othman, M.B.H.; Javed, F.; Ahmad, Z.; Akil, H.M. Classification, Processing and Application of Hydrogels: A Review. Mat. Sci. Eng. C 2015, 57, 414-433. [CrossRef]

7. Perkins, D.N.; Brune Drisse, M.N.; Nxele, T.; Sly, P.D. E-Waste: A Global Hazard. Ann. Glob. Health 2014, 4, 286-295. [CrossRef]

8. Kabir, S.M.F.; Sikdar, P.P.; Haque, B.; Bhuiyan, M.A.R.; Ali, A.; Islam, M.N. Cellulose-Based Hydrogel Materials: Chemistry, Properties and Their Prospective Applications. Prog. Biomater. 2018, 7, 153-174. [CrossRef]

9. Kang, H.; Liu, R.; Huang, Y. Cellulose-Based Gels. Macromol. Chem. Phys. 2016, 217, 1322-1334. [CrossRef]

10. Kayra, N.; Aytekin, A.Ö. Synthesis of Cellulose-Based Hydrogels: Preparation, Formation, Mixture, and Modification. In Cellulose-Based Superabsorbent Hydrogels, 1st ed.; Part II, Ch. 14; Springer International Publishing: Cham, Switzerland, 2018; pp. 1-28. [CrossRef]

11. Isik, M.; Sardon, H.; Mecerreyes, D. Ionic Liquids and Cellulose: Dissolution, Chemical Modification and Preparation of New Cellulosic Materials. Int. J. Mol. Sci. 2014, 15, 11922-11940. [CrossRef]

12. Sannino, A.; Demitri, C.; Madaghiele, M. Biodegradable Cellulose-Based Hydrogels: Design and Applications. Materials 2009, 2, 353-373. [CrossRef]

13. Hasan, A.M.A.; Abdel-Raouf, M.E.-S. Cellulose-Based superabsorbent hydrogels. In Cellulose-Based Superabsorbent Hydrogels, 1st ed.; Part I, Ch. 8; Springer International Publishing: Cham, Switzerland, 2018; pp. 246-264. [CrossRef]

14. Jabbour, L.; Bongiovanni, R.; Chaussy, D.; Gerbaldi, C.; Beneventi, D. Cellulose-Based Li-Ion Batteries: A Review. Cellulose 2013, 20, 1523-1545. [CrossRef]

15. Li, Y.; Wang, J.; Liu, X.; Zhang, S. Towards a Molecular Understanding of Cellulose Dissolution in Ionic Liquids: Anion/Cation Effect, Synergistic Mechanism and Physicochemical Aspects. Chem. Sci. 2018, 9, 4027-4043. [CrossRef] [PubMed]

16. Kasprzak, D.; Stępniak, I.; Galiński, M. Electrodes and Hydrogel Electrolytes Based on Cellulose: Fabrication and Characterization as EDLC Components. J. Solid State Electrochem. 2018, 22, 3035-3047. [CrossRef] 
17. Yang, L.; Song, L.; Feng, Y.; Cao, M.; Zhang, P.; Zhang, X.; Yao, J. Zinc Ion Trapping in Cellulose Hydrogel as Solid Electrolyte for Safe and Flexible Supercapacitor. J. Mater. Chem. A 2020, 8, 12314-12318. [CrossRef]

18. Navarra, M.A.; Dal Bosco, C.; Moreno, J.S.; Vitucci, F.M.; Paolone, A.; Panero, S. Synthesis and Characterization of Cellulose-Based Hydrogels to Be Used as Gel Electrolytes. Membranes 2015, 5, 810-823. [CrossRef]

19. Wang, H.; Wu, J.; Qiu, J.; Zhang, K.; Shao, J.; Yan, L. In Situ Formation of a Renewable Cellulose Hydrogel Electrolyte for High-Performance Flexible All-Solid-State Asymmetric Supercapacitors. Sustain. Energy Fuels 2019, 3, 3109-3115. [CrossRef]

20. Shi, Y.; Zhang, Q.; Zhang, Y.; Jia, L.; Xu, X. Promising and Reversible Electrolyte with Thermal Switching Behavior for Safer Electrochemical Storage Devices. ACS Appl. Mater. Interfaces 2018, 10, 7171-7179. [CrossRef]

21. Gajewski, P.; Béguin, F. Hydrogel-Polymer Electrolyte for Electrochemical Capacitors with High Volumetric Energy and Life Span. ChemSusChem 2020, 13, 1876-1881. [CrossRef]

22. Sannino, A.; Esposito, A.; De Rosa, A.; Cozzolino, A.; Ambrosio, L.; Nicolais, L. Biomedical Application of a Superabsorbent Hydrogel for Body Water Elimination in the Treatment of Edemas. J. Biomed. Mater. Res. Part A 2003, 67, 1016-1024. [CrossRef]

23. Del Agua, I.; Marina, S.; Pitsalidis, C.; Mantione, D.; Ferro, M.; Iandolo, D.; Sanchez-Sanchez, A.; Malliaras, G.G.; Owens, R.M.; Mecerreyes, D. Conducting Polymer Scaffolds Based on Poly(3,4Ethylenedioxythiophene) and Xanthan Gum for Live-Cell Monitoring. ACS Omega 2018, 3, 7424-7431. [CrossRef] [PubMed]

24. Mantione, D.; Del Agua, I.; Schaafsma, W.; Elmahmoudy, M.; Uguz, I.; Sanchez-Sanchez, A.; Sardon, H.; Castro, B.; Malliaras, G.G.; Mecerreyes, D. Low-Temperature Cross-Linking of PEDOT:PSS Films Using Divinylsulfone. ACS Appl. Mater. Interfaces 2017, 9, 18254-18262. [CrossRef] [PubMed]

25. Ko, H.F.; Sfeir, C.; Kumta, P.N. Novel Synthesis Strategies for Natural Polymer and Composite Biomaterials as Potential Scaffolds for Tissue Engineering. Philos. Trans. R. Soc. A Math. Phys. Eng. Sci. 2010, 368, 1981-1997. [CrossRef] [PubMed]

26. Alesanco, Y.; Palenzuela, J.; Viñuales, A.; Cabañero, G.; Grande, H.J.; Odriozola, I. Polyvinyl Alcohol-Borax Slime as Promising Polyelectrolyte for High-Performance, Easy-to-Make Electrochromic Devices. ChemElectroChem 2015, 2, 218-223. [CrossRef]

27. Shimojo, A.A.M.; Pires, A.M.B.; Lichy, R.; Santana, M.H.A. The Performance of Crosslinking with Divinyl Sulfone as Controlled by the Interplay between the Chemical Modification and Conformation of Hyaluronic Acid. J. Braz. Chem. Soc. 2015, 26, 506-512. [CrossRef]

28. Sannino, A.; Madaghiele, M.; Conversano, F.; Mele, G.; Maffezzoli, A.; Netti, P.A.; Ambrosio, L.; Nicolais, L. Cellulose Derivative-Hyaluronic Acid-Based Microporous Hydrogels Cross-Linked through Divinyl Sulfone (DVS) to Modulate Equilibrium Sorption Capacity and Network Stability. Biomacromolecules 2004, 5, 92-96. [CrossRef]

29. Anbergen, U.; Oppermann, W. Elasticity and Swelling Behaviour of Chemically Crosslinked Cellulose Ethers in Aqueous Systems. Polymer 1990, 31, 1854-1858. [CrossRef]

30. Orhan, B.; Ziba, C.A.; Morcali, M.H.; Dolaz, M. Synthesis of hydroxyethyl cellulose from industrial waste using microwave irradiation. Sustain. Environ. Res. 2018, 6, 403-411. [CrossRef]

31. Sun, N.; Wang, T.; Yan, X. Synthesis and investigation of a self-assembled hydrogel based on hydroxyethyl cellulose and its in vivo ibuprofen drug release characteristics. RSC Adv. 2017, 7, 9600. [CrossRef]

32. Astrini, N.; Anah, L.; Haryono, A. Crosslinking Parameter on the Preparation of Cellulose Based Hydrogel with Divynilsulfone. Procedia Chem. 2012, 4, 275-281. [CrossRef]

33. Zuidema, J.M.; Rivet, C.J.; Gilbert, R.J.; Morrison, F.A. A Protocol for Rheological Characterization of Hydrogels for Tissue Engineering Strategies. J. Biomed. Mater. Res. Part B Appl. Biomater. 2014, 102, 1063-1073. [CrossRef] [PubMed]

34. Bhosale, P.S.; Berg, J.C. Acoustic Spectroscopy of Colloids Dispersed in a Polymer Gel System. Langmuir 2010, 26, 14423-14426. [CrossRef] [PubMed]

35. Zhou, D.; Xie, D.; Shi, F.; Wang, D.H.; Ge, X.; Xia, X.H.; Wang, X.L.; Gu, C.D.; Tu, J.P. Crystalline/amorphous tungsten oxide core/shell hierarchical structures and their synergistic effect for optical modulation. J. Colloid Interface Sci. 2015, 460, 200-208. [CrossRef] [PubMed] 
36. Hajzeri, M.; Colovic, M.; Vuk, A.S.; Posset, U.; Orel, B. Semi-Solid Gel Electrolytes for Electrochromic Devices. Mater Technol. 2011, 45, 433-438.

37. Alesanco, Y.; Viñuales, A.; Ugalde, J.; Azaceta, E.; Cabañero, G.; Rodriguez, J.; Tena-Zaera, R. Consecutive anchoring of symmetric viologens: Electrochromic devices providing colorless to neutral-color switching. Sol. Energy Mater. Sol. Cells 2018, 177, 110-119. [CrossRef]

38. Alesanco, Y.; Viñuales, A.; Cabañero, G.; Rodriguez, J.; Tena-Zaera, R. Colorless-to-Black/Gray Electrochromic Devices Based on a Single 1-Alkyl-1'-Aryl Asymmetric Viologen-Modified Monolayered Electrodes. Adv. Opt Mater. 2017, 5, 1600989. [CrossRef]

39. Alesanco, Y.; Viñuales, A.; Rodriguez, J.; Tena-Zaera, R. All-in-One Gel-Based Electrochromic Devices: Strengths and Recent Developments. Materials 2018, 11, 414. [CrossRef]

40. Alesanco, Y.; Viñuales, A.; Palenzuela, J.; Odriozola, I.; Cabañero, G.; Rodriguez, J.; Tena-Zaera, R. Multicolor Electrochromics: Rainbow-Like Devices. ACS Appl. Mater. Interfaces 2016, 8, 14795-14801. [CrossRef]

41. Alesanco, Y.; Viñuales, A.; Cabañero, G.; Rodriguez, J.; Tena-Zaera, R. Colorless to Neutral Color Electrochromic Devices Based on Asymmetric Viologens. ACS Appl. Mater. Interfaces 2016, 8, 29619-29627. [CrossRef]

42. Ledwon, P.; Andrade, J.R.; Lapkowski, M.; Pawlicka, A. Hydroxypropyl Cellulose-Based Gel Electrolyte for Electrochromic Devices. Electrochim. Acta 2015, 159, 227-233. [CrossRef]

43. Lin, S.Y.; Chen, Y.C.; Wang, C.M.; Wen, C.Y.; Shih, T.Y. Study of MoO 3-NiO Complementary Electrochromic Devices Using a Gel Polymer Electrolyte. Solid State Ion. 2012, 212, 81-87. [CrossRef]

44. Kiristi, M.; Bozduman, F.; Gulec, A.; Teke, E.; Oksuz, L.; Oksuz, A.U.; Deligöz, H. Complementary All Solid State Electrochromic Devices Using Carboxymethyl Cellulose Based Electrolytes. J. Macromol. Sci. Part A Pure Appl. Chem. 2014, 51, 481-487. [CrossRef]

45. Ramos, A.M.; Pereira, S.; Cidade, M.T.; Pereira, G.; Branquinho, R.; Pereira, L.; Martins, R.; Fortunato, E. Preparation and Characterization of Cellulose Nanocomposite Hydrogels as Functional Electrolytes. Solid State Ion. 2013, 242, 26-32. [CrossRef]

46. Ngamaroonchote, A.; Chotsuwan, C. Performance and Reliability of Cellulose Acetate-Based Gel Electrolyte for Electrochromic Devices. J. Appl. Electrochem. 2016, 46, 575-582. [CrossRef]

47. Xiao, S.; Zhang, Y.; Ma, L.; Zhao, S.; Wu, N.; Xiao, D. Easy-to-Make Sulfonatoalkyl Viologen/Sodium Carboxymethylcellulose Hydrogel-Based Electrochromic Devices with High Coloration Efficiency, Fast Response and Excellent Cycling Stability. Dye. Pigment. 2020, 174. Ahead of Print. [CrossRef]

48. Mortimer, R.J.; Varley, T.S. Quantification of Colour Stimuli through the Calculation of CIE Chromaticity Coordinates and Luminance Data for Application to in Situ Colorimetry Studies of Electrochromic Materials. Displays 2011, 32, 35-44. [CrossRef]

49. Mortimer, R.J.; Varley, T.S. In Situ Spectroelectrochemistry and Colour Measurement of a Complementary Electrochromic Device Based on Surface-Confined Prussian Blue and Aqueous Solution-Phase Methyl Viologen. Sol. Energy Mater. Sol. Cells 2012, 99, 213-220. [CrossRef]

50. Mortimer, R.J.; Varley, T.S. Novel Color-Reinforcing Electrochromic Device Based on Surface-Confined Ruthenium Purple and Solution-Phase Methyl Viologen. Chem. Mater. 2011, 23, 4077-4082. [CrossRef]

51. Yao, D.D.; Rani, R.A.; O'Mullane, A.P.; Zadeh, K.K.; Ou, J.Z. Enhanced Coloration Efficiency for Electrochromic Devices Based on Anodized Nb2O5/Electrodeposited MoO3 Binary Systems. J. Phys. Chem. C 2014, 118, 10867-10873. [CrossRef]

52. Su, Y.; Yang, F.; Zhou, L.; Geng, Y.; Zhang, J.; Jiang, M. Flexible and Tailorable Alkylviologen/Cellulose Nanocrystals Composite Films for Sustainable Applications in Electrochromic Devices. ChemElectroChem 2018, 5, 1407-1414. [CrossRef]

53. INNPAPER. Available online: https://innpaper.eu/ (accessed on 5 November 2020).

54. Khan, S.; Lorenzelli, L.; Dahiya, R.S. Technologies for printing sensors and electronics over large flexible substrates: A review. IEEE Sens. J. 2015, 6, 3164-3185. [CrossRef]

55. Mainar, A.R.; Iruin, E.; Colmenares, L.C.; Kvasha, A.; de Meatza, I.; Bengoechea, M.; Leonet, O.; Boyano, I.; Zhang, Z.; Blazquez, J.A. An Overview of Progress in Electrolytes for Secondary Zinc-Air Batteries and Other Storage Systems Based on Zinc. J. Energy Storage 2018, 15, 304-328. [CrossRef] 
56. Tang, B.; Shan, L.; Liang, S.; Zhou, J. Issues and Opportunities Facing Aqueous Zinc-Ion Batteries. Energy Environ. Sci. 2019, 12, 3288-3304. [CrossRef]

57. Huang, S.; Zhu, J.; Tian, J.; Niu, Z. Recent Progress in the Electrolytes of Aqueous Zinc-Ion Batteries. Eur. J. Chem. 2019, 25, 14480-14494. [CrossRef]

Publisher's Note: MDPI stays neutral with regard to jurisdictional claims in published maps and institutional affiliations.

(C) 2020 by the authors. Licensee MDPI, Basel, Switzerland. This article is an open access article distributed under the terms and conditions of the Creative Commons Attribution (CC BY) license (http://creativecommons.org/licenses/by/4.0/). 